the fact that the earliest biochemical pregnancy test will not disclose a pregnancy until 10 days after fertilisation. Should we therefore revert to the simple stalwart 10 day rule? The answer is no, because the risks of diagnostic irradiation of a conceptus are not proved to be of any importance until organogenesis occurs in the third week after conception. ${ }^{312} 13$

With one anxiety controlled, another has now emerged. Biological research suggests that there may be a risk from irradiation of the ovum during the seven weeks before ovulation. ${ }^{1314}$ Perhaps the patient should be asked before the $x$ ray examination not only "When did your last period begin?" but also "Are you intending to become pregnant within the next seven weeks?"

There is much advice but little real ruling. Local protocols must be drawn up and should take account of the points shown in the box (M Fitzgerald, personal communication).

The National Radiological Protection Board claims that it deliberately left to clinicians the manner in which its recommendations of $1985^{6}$ should be used to replace the 10 day rule. ${ }^{15}$ The board is quite right - we must commend, not criticise, them for allowing us this clinical freedom. We must, however, examine the advice we have been given and discuss the guidelines from our colleges before agreeing policies for each department. We cannot hide unthinkingly behind inflexible rules, 10 day or other. Instead, we must make thoroughly informed decisions about investigating patients while observing the one central rule - to minimise the exposure of fetuses.

In summary, $x$ rays directed close to the uterus in women of childbearing ability carry risks to a pregnancy that may be present or may happen up to seven weeks after that $x$ ray examination. With our current state of knowledge it is right that the 10 day rule is abandoned-it should never have existed as a rule but as an option to be used when appropriate. Instead, women of childbearing ability should be asked the pregnancy question, and if the answer is other than "No" then the fully informed radiologist or referring clinician must decide whether or not to proceed with the examination.

\section{RUTH PEARSON}

Consultant Radiologist,

Queen Mary's University Hospital,

Roehampton,'London SW15 5PM

1 International Commission on Radiological Protection. Recommendations of the ICRP. Oxford: Pergamon Press, 1964. (ICRP publication 6.)

2 International Commission on Radiological Protection. Recommendations of the ICRP. Ann ICRP 1977; 1 (No 3). (ICRP publication 26.)

3 International Commission on Radiological Protection. Protection of the patient in diagnostic radiology. Ann ICRP 1982;9 (No 2/3). (ICRP publication 34.)

4 Otake $M$, Schull VJ. In utero exposure to $A$-bomb radiation and mental retardation: a reassessment. Br f Radiol 1984;57:409-14.

International Commission on Radiological Protection. Statement from the 1983 Washington meeting of ICRP. Ann ICRP 1984;14.

National Radiological Protection Board. Exposure to ionising radiation of pregnant women: advice on the diagnostic exposure of women who are, or may be, pregnant. London: HMSO, 1985. (ASP8.)

Roebuck EJ. Advice on the diagnostic exposure of women who are, or may be, pregnant. Royal College of Radiologists Newsletter 1985;18:7-9.

8 Acheson ED. Exposure to ionising radiation of pregnant women: advice on the diagnostic exposure of women who are, or who may be, pregnant. London: Department of Health and Social Security, women who are, or who

9 College of Radiographers and Royal College of Radiologists. Guidelines for implementation of ASP8. Exposure to ionising radiation of pregnant women: advice on the diagnostic exposure of women who are, or who may be, pregnant. London: College of Radiographers and Royal College of Radiologists, 1986

10 International Commission on Radiological Protection. Protection of the patient in nuclear medicine. Ann ICRP 1987;17. (ICRP publication 52.)

11 National Radiological Protection Board, Health and Safety Executive, and Department of Health and Social Security. Guidance notes for the protection of persons against ionising radiations arising from medical and dental use. London: HMSO, 1988.

12 Goulden ME, Murray RC. Medical radiation and possible adverse effects on the human embryo. In: Meyn RE, Withers HR, eds. Radiation biology in cancer research. New York: Raven Press, 1980. 3 Russell JGB. The rise and fall of the 10-day rule. Br f Radiol 1986;59:3-6.

14 Baker TG, Neal P. Action of ionising radiation in the mammalian ovary. In: Zuckerman S, Weir BJ, eds. The ovary. Vol 1. New York: Academic Press, 1977:1-47.

Anonymous. Detailed advice or self reliance? [Editorial.] National Radiological Protection Board Bulletin 1986 (Jan): 3 .

\title{
Consent and people with mental handicap
}

\section{Nobody but the patient may give consent}

Gaining consent for a procedure from an adult with mental handicap living in the community is complex. ${ }^{1}$ When most people with mental handicap lived in large institutions consent was provided through the paternalism of the physician superintendent or by relatives. Even those who had enough understanding to give consent were not allowed to do so. Because of increasing community care, rejection of the concept of infantilism, and a greater awareness of human rights the legal position on consent for these people has been reviewed: it became clear that no one but the adults themselves could give consent, however handicapped they might be and whatever their degree of legal competence. ${ }^{2}$ Proxy consent from anyone was not valid in law. In particular, "blanket" consent forms offering a variety of consents for possible future events are useless, invalid, and an example of bad paternalistic practice. ${ }^{3}$

The Mental Health Acts of 1959 and 1983 provided nothing more in the way of advice. Under the 1959 act guardians could give proxy consent, but so few were appointed that the picture did not change much when this power was removed in the 1983 Mental Health Act. Despite this there is a move to reintroduce the guardian's capacity to give consent as one way of filling the legal vacuum.

Some adults with a mental handicap understand enough and are legally competent to give valid consent when the explanation is simple, repeated, and given by someone they trust. Some may sign their own name, and others may make a witnessed mark or thumbprint. Persuasion should not in these circumstances limit the autonomy of the adults, who may still have little experience of making choices in their everyday lives, but sometimes the wrong choice is made and may need to be overridden if life is to be saved. Others, however, will never understand because of the severity of their handicap, but no one else can give consent.

When the treatment is not controversial the doctor needs to go ahead if possible with the agreement (but not the consent) of the usual carer and next of kin, acting "in good faith" and showing "a duty of care." These are yardsticks by which he or she will be appraised. "Acting in good faith" is usually easy to define: it includes procedures such as endoscopy for a suspected cancer, laparotomy for an acute abdominal condition, or aspirin for a headache. In extreme emergency the doctor intervenes without consent using the "principle of necessity" as he would for someone who is unconscious. People with a mental handicap should not be included in clinical trials or any other activity that is not of direct therapeutic benefit to them.

The unsigned consent form is often, however, seen as unacceptable, and a social worker may be sent to seek a long lost relative while everyone waits impatiently. ${ }^{4}$ Junior doctors, who may have been taught the current state of the law, may still insist on a signature in deference to their seniors. Often someone in the mental handicap service signs the form to allow the intervention to proceed-thus per- 
petuating the paternalistic system. Sadly, all this adds to the image that people with a mental handicap do not fit comfortably into the community.

The common law "principle of necessity" is the one that five law lords said this year should be stretched to controversial situations such as sterilisation, which has medical, social, and eugenic overtones in legally incompetent people. ${ }^{5}$ The other principle is that of "acting in the best interests of the patient," which is interpreted to mean that the doctor should act in accordance with a substantial body of medical opinion or follow the established medical practice of the day. It is, however, in the controversial situation that there may not be an established, unanimous, or even a majority intervention. Anyone going to law for an absolute ruling for consent will be disappointed. The judge cannot given consent, and the responsibility can only remain with the doctor-who will, however, be prudent to gain the agreement from the court so that his anticipated controversial intervention "will not be unlawful."

These operational definitions may allow too much room for medical manoeuvre and insufficient backing for decisions made. Thankfully, the Law Commission and the Department of Health are investigating the law of consent, as such piecemeal guidance and legislation may not only incompletely protect the rights of the handicapped person but may infringe those rights if the seemingly unsupported doctor errs on the side of extreme caution. ${ }^{6}$

A notice summarising the correct legal position for this client group may with benefit be placed in all wards and departments of the local general hospital (J Bicknell, T R Gould, paper circulated within Wandsworth Health Authority). Adults with a mental handicap need their majority to be respected and the state of their legal competence assessed and acknowledged. It is hoped that with further clarification of the law it should be possible to maximise their autonomy, minimise paternalism, and provide all the health care that they require.

JOAN BICKNELL

Professor of the Psychiatry of Mental Handicap,

Department of Psychiatry,

St George's Hospital Medical School,

London SW17 0RT

Lord Scarman. Consent, communication and responsibility. $\mathcal{F} R$ Soc Med 1986;79:697-700.

2 Dyer C. Consent and the mentally handicapped. Br Med f 1987;295:257-8.

3 Royal College of Psychiatrists. Interim guidelines on consent to medical and surgical treatment, contraception, sterilisation and abortion in the mentally handicapped. Bulletin of the Royal College of Psychiatrists, 1986;10:184-5.

4 Medical Defence Union. Consent to treatment. London: Medical Defence Union, 1986.

5 Dyer C. Law lords give reasons for their decision on consent. $\mathrm{Br}$ Med $\mathrm{f}$ 1989;298:1542.

6 Dyer C. Law making for the mentally handicapped. Br Med f 1989;298:875.

\section{Immunotherapy of human cancers}

\section{New approaches hold out promise}

For years now attempts at treating cancers by immunotherapy have given disappointing results. These failures suggest that the mutations found in most human cancers do not change their antigenicity enough to make them suitable immunological targets. When antigenic differences are shown ${ }^{1}$ - for example, in choriocarcinoma, hypernephroma, leukaemia, medullary breast cancer, melanoma, neuroblastoma, sarcoma, and some endocrine or chemically induced tumours, such as in the bladder and lung - they are often recognised only by nonhuman species. When antibodies raised in animals are used clinically the recipient patient may reject the antibodies. Furthermore, many tumour antigens are not useful targetsfor example, B cell tumours secrete "smokescreens" of free idiotype, and these mop up any antibody-drug complexes aimed at the tumour. Studies in animals have shown that such treatment is most successful when the tumour has been reduced to a minimum by surgery or drugs and the smokescreen is thin.

Immunotherapy is described as active when the host's immune defences are recruited, passive when immune cells or antibodies from other donors are introduced, and adoptive when donor immur. ieucocytes confer messages to nost cells.

The best prospect for active cancer immunotherapy is prophylaxis. A good example is immunisation against hepatitis B of the population of Singapore to prevent hepatocarcinoma. Other possibilities of this type include vaccines against the Epstein-Barr virus to counter endemic nasopharyngeal cancers and lymphomas, against papillomavirus to reduce cervical cancer, and against HIV to reduce Kaposi's sarcoma.

Adjuvants augment a pre-existing immune response, but their results have been poor - probably because most patients with cancer have immunological defects. The lesson from animal studies applies here too: adjuvant treatment is most likely to be successful in patients with minimal tumour who are no longer having cytoreductive treatment. The new generations of adjuvants, such as muramyldipeptide and its derivatives, may prove effective in these circumstances. The term immunostimulant is best reserved for substances producing an immune response that was previously undetectable. Most modifiers of the biological response do not cause any proliferation of lymphocytes, and even substances such as interleukin- 2 tend simply to stimulate the patient's immune system to produce more of the same responses - which have already proved ineffective. Some preparations of thymic factors do increase the number of human lymphocytes bearing OKT6. (CDl), a marker for the "generation of diversity," by rearrangement of genes. The new clones that emerge in such responses may include some with activity against tumour antigens. If the tumour mass is too large the amount of antigen produced may delete such clones. Attempts to reduce tumour mass by cytoreductive agents may, however, eliminate dividing clones. The balance can be achieved: careful use of thymic factors in patients with minimal residual malignant melanoma or lung cancer has lowered recurrence rates appreciably and increased survival. ${ }^{2}$

Adoptive immunotherapy has been of limited success in animals ${ }^{3}$ and humans. ${ }^{+}$In laboratory experiments with cultures of lymphoid cells, fetal calf serum (whose thymic factors can be lymphopoietic) has been shown to diversify the subsequent clones. Educating a patient's own lymphoid cells in vitro was the dream of previous pioneers such as Nadler and Moore ${ }^{5}$ and it has the advantage of avoiding the transfer of retrovirus. Such an approach could be improved by using long term bone marrow cultures with the lymphoid precursors under the influence of truly lymphopoietic immunostimulants. These tailor made treatments, however, would be very expensive; they could never be widely applicable to the one third of the population who will develop cancer. These should probably be reserved for children under 3-or for 